\title{
Europe 2020 Strategy and New Policies for Marginal Areas
}

\author{
Vincenzo Provenzano ${ }^{1, a}$, Maria Rosaria Seminara ${ }^{1, b}$ \\ ${ }^{1}$ University of Palermo, Italy \\ avincenzo.provenzano@unipa.it, ${ }^{b}$ mariarosaria.seminara@unipa.it
}

Keywords: Europe 2020, Marginality, Local Development, Governance, Clusters, Rural Areas.

\begin{abstract}
Marginality should be seen as an a asset rather than a liability for a region or a community. Marginality reflects a strategy of economic development, and this paper also seeks institutional means for championing marginality over conformity.
\end{abstract}

\section{Introduction}

The Europe 2020 strategy aims to boost the EU economy over the next decade, creating the conditions for a competitive economy that will allow you to reach to the territories of the Member States to exploit existing resources, focusing on a sustainable and inclusive development.

It sets out priority objectives to be pursued and achieved, the instruments to be used and the method of governance to be adopted in this decade [1].

In a time of Geo-political and social metamorphosis, the EU aims to become a smart, sustainable and inclusive economy. These three mutually reinforcing priorities that aim to help the EU and its Member States to achieve high levels of employment, productivity and social cohesion.

Europe 2020 aims to fill the gaps in the patterns of growth that have characterized modern economies, creating the conditions for alternative models of growth.

The success of the strategy depends on a determined and focused action both at European level that at national level. Member States must direct their policies under the seven priority initiatives that the strategy is, therefore focusing on innovation, digital economy, employment, youth, industrial policy, poverty and the efficient use of resources.

Both the European policies that national policies give way to a programming period starting from the knowledge of the area and its planning.

The administrative decentralization, the planning from the bottom and the evolutions of regional policy of the European Union are the main elements of change, which rely on local actors play a strategic role and unreleased in the management of its own territory.

Each country is characterized by several economic, social, spatial differences with an inhomogeneous distribution of resources, money, work activities, infrastructure, probably not to network but that back in the game of phases of structural change in the economy. Each region should, therefore, be able to follow its own trend and develop a specific strategy.

It's necessary a local approach that takes into account of the geographical circumstances, of development and environmental, as well as of the situations and the regional priorities. Regional development must, therefore, consider the possibility of using marginal areas, often excluded from the processes of change, but holders of economic and environmental resources hardly explored, appropriate and compatible to restructuring processes of the economic system.

\section{The National Strategy for Inland Areas}

The implementation of the strategy requires, therefore, a local approach that takes into account the geographical, environmental and development circumstances, individuality and uniqueness of European territories.

Since the 90s of the last century there has been a gradual transformation of intervention policies for the development of marginal areas traditionally designed using analysis issues such as the 
integrated and sustainable development, the exploitation of endogenous resources and the development from below. There are a number of contributions in the literature based on methodologies that nowadays are revised to rethink the role of the state in the dynamics of development and more broadly in the role of institutions in local development planning and in mobilization of endogenous potentiality of less favoured regions as a tool to improve competitiveness. The development, therefore, as a progressive enhancement of existing assets, not used and not yet networked.

The Italian Inner Areas represent a considerable strategic option for Planning 2014-2020. An important part of the Italian territory is characterized by a spatial organization based on "small towns," often small in size, which in many cases do not have accessibility to essential services. The term "internal areas", collects the specificity of these territories, areas significantly distant from the offer centers of basic services (education, health, and mobility), with important environmental resources (water resources, agricultural systems, forests, natural landscapes and human) and cultural (archaeological, historical settlements, abbeys, small museums, craft centers); deeply different, for natural systems and as a result of centuries-old processes of human settlement.

The Ministry of Territorial Cohesion, last 21gennaio 2014 published a draft of a document that explains "The National Strategy for the Internal areas: definition, objectives, instruments and governance."

The strategy involves the initial involvement of a limited number of areas, one for Region, a national coordination and an execution by different levels of government in strong coordination between them. It put itself as an ultimate goal that to improve the demographic trends in place in internal areas: reduction of migration, attraction of new residents, recovery of births, changing of composition for age in favor of the younger classes.

To achieve these results, the strategy identifies two interdependent and joint actions:

1. the adjustment of supply to essential services

2. local projects.

The first action is defined as a precondition for local development, and refers to availability in the territory of an adequate supply of basic goods / services.

The supply of goods and services such as health, education and vocational training, as well as mobility became essential for the development of strategy, which aims to create the conditions necessary to ensure that an area provides a sufficient basis for the permanence of residents and creates the possibility of attracting new residents.

The intervention on the development preconditions calls into play the different institutional actors, and uses different financial resources.

The second intervention of strategy refers to the promotion of "local development projects", which should trigger virtuous circles of development in the territories.

The areas of local projects are identified in the strategy and refer to:

1. active protection of land / environmental sustainability;

2. enhancement of natural / cultural capital and tourism;

3. enhancement of agro-food systems;

4. activation of chains of renewable energy;

5. know-how and craftsmanship.

The action lines are converging each with other and are designed to promote the development through projects funded by different European funds available, the other directed to these same areas to ensure adequate levels of citizenship in certain essential services (health education and mobility), especially through a re-balancing of the ordinary policy decisions.

The logic of the strategy resides in actions that simultaneously help both adjustment policies of citizenship services (health, education, mobility) and local development policies, and that will lead to the increase of employment, of population, and of the use of territorial capital so that they create economic development processes that allow a reversal of demographic trends in inland areas. 
The inland area include:

- $61 \%$ of the national territory,

- $23 \%$ of the Italian population;

- more than 4,000 municipalities with an average of 3,000 people everyone.

A significant part of the inland areas has withstand gradually after World War II, a process of marginalization marked by: population decline, sometimes below the critical threshold; reduction in employment and land use; local offer decreasing of public and private services, social costs, such as the imbalance hydro-geological and degradation of cultural and landscape heritage.

But the internal areas also show examples of "good policy" and "good practices". Some areas have experienced a particular attention by politics that have valued the environmental and cultural resources, helping to trigger in these territories virtuous circles of development, forms of dialogue and cooperation among all stakeholders present in places.

The areas that for a long time have been on the sidelines, therefore have the opportunity to implement a new way of doing business, and are probably the ones most likely to innovation and creativity.

\section{The value of the marginality}

The regional policies play a major role, particularly in those regions that are located in disadvantaged situations. The actions of local actors become fundamental in the direction of development of their area.

The marginal areas, in a positive and soothed, possess economic and environmental resources but little explored consistent with an alternative model of growth proposed by Europe.

The marginal areas are often places incubators business changes. In them is disseminated a popular information that allows a localized learning, thanks to the interaction between local actors that are part of the same productive and cultural system $[2,3,4]$.

The marginality [5] can be territorial element of advantage, meets the requirements for alternative models of development.

Regional development, and particularly the development of regions "weaker", requires incentives to those fertile territories, pervaded by business dynamism. Entrepreneurship has received in the recent past, a prominent place in economic theory, as it is increasingly recognized that entrepreneurship plays a vital role in economic growth. In contrast to the theories of the traditional growth, in which technological progress and innovation have been considered as an exogenous force (manna from heaven), theories of the modern endogenous growth take for granted that innovation and entrepreneurship are endogenous forces guided by various actors in the economic systems and that can be influenced by public policies clever. This new theoretical framework places a lot of emphasis on critical factors of success such as competition, vested interests, $\mathrm{R} \& \mathrm{D}$, knowledge spillovers, human capital, industrial culture and entrepreneurial skills [6]. The economic process is intended as a conversation and coordination, the subjects of the process aren't factors but reflexive human actors, both individual and collective, and the nature of economic accumulation is not only in material goods but also in relational activities [7]. Such an environment fosters the creative and innovative personality, or entrepreneurs capable of an internal change in the economic structure. A paradox of globalization is that the sites are actually become more important because the spatial proximity to knowledge may confer a competitive advantage [8]. The continuous search for new knowledge becomes imperative for companies and can come from two main sources [9]. First, firms acquire knowledge that learning based on their own internal resources. Learning by doing is without a doubt the most pervasive means by which they do it, especially in the case of small businesses [10]. Second, firms also learn appropriating knowledge produced by external sources, from other companies or institutions such as universities or research institutions. The ways through which companies draw from the knowledge are many and varied, including written texts, informal 
conversations, inter-firm mobility of workers, strategic alliances, and so on. In this way, the knowledge produced in a territory is acquired through the spatial proximity [11].

The sociological and economic theories agree on the existence of possible synergistic effects in the implementation of development policies, coming from the dialogue between the institutions and civil society, expanding the number of subjects participating to the same definition of local growth strategy [12] .

\section{The clusters, a different way of thinking about the economy}

In the last twenty years has lost consistency the key concept of stability, which has been supplanted by that of flexibility, understood as "the ability to adapt quickly to external changes, penalty the not survival of the same organization" [13]. Looking for more flexibility then it has joined the continuous pursuit of quality of the products. The search for flexibility and quality, and thus innovation, are now more closely linked to cooperation processes involving the sharing of a common language, forms of tacit knowledge that make it possible to exploit better the peculiarities of marginal lands. The Europe hopes for greater competitiveness, focusing on the interconnection sector, on those groups of companies and institutions located on the same area, on clusters that represent a significant economic sector [14]. It is also necessary to grasp the relational aspect, the relationships that develop between companies, institutions, organizations and communities [15], which may be enclosed with the term social capital, since, network of relationships, the glue that holds together all stakeholders within a cluster [16,17]. the research in the area of economic and social relations becomes search of resources, through a strategic approach can enhance the competitiveness of an area. The competition and innovation is made possible by the presence of common values and collective interests that transcend those of the individual. The search for flexibility and quality not only leads to a restructuring that increases the autonomy of the internal structures of companies, but especially to a greater need for external cooperation. The proximity in geographical, cultural, and institutional terms grants access to special reports, to a better information, to strong incentives, and other advantages in terms of productivity and productivity growth that are difficult to tap from a distance. Mechanisms of formal and informal organization and cultural norms play a key role in the development and operation of the cluster that provides a vehicle to bring businesses and local institutions in a constructive dialogue collective. Clusters represent a different way of thinking about national, regional and local economies, with a change of hierarchies and new roles of roles businesses. Draw the boundaries of the cluster involves a creative and informed process, with the understanding of linkages and complementarity across all industries and institutions. The formation of clusters, instruments to enhance the competitive strength of a place, it can become the tool to take advantage of the European financial resources.

\section{Conclusions}

Collaboration, and relationship between regional and local institutions, universities, research centers, businesses and communities are crucial aspects in the change of economic policy management. Compete globally poses challenges at the local level and the formation of clusters as an engine of development, can make the necessary change required in this phase of economic difficulties. The National Strategy for inland areas then attempts to establish the areas that can be considered real laboratories for the formation of clusters, which should trigger the territories in question, alternative models of development consistent with the EU directives, demographic processes inverse with respect to those current, and creative ideas for innovative forms of entrepreneurship. The key challenge is to foster a balanced development of rural areas by enabling them to capitalize on their distinctive territorial capital and thus "turn diversity into strength"[18]. Social innovation relates to the development of new forms of organisations and interactions to respond to societal challenges. 


\section{References}

[1] V. Provenzano: La Strategia Europa 2020 e la marginalità del Mezzogiorno, XXXII Conferenza Italiana di Scienze Regionali, AISRE, Torino (2011)

[2] R. Camagnini: Innovation Networks: Spatial Perspectives, London: Belhaven Press (1991)

[3] M. Storper: The limits to Globalization: Technology District and International Trade, Economic Geography, 68,1 (1992) pp. 60-93

[4] M. Storper: Regional "worlds" of Production: Learning and innovation in the Technology Districts of France, Italy and the USA, Regional Studies, 27, 5 (1993), pp. 433-455

[5] V. Provenzano: Il valore della marginalità in un mondo conformista. Un diverso modo di pensare lo sviluppo, Carocci Editore, Roma (2008)

[6] M. M. Fisher, P. Nijkamp: Entrepreneurship and Regional Development, In: R. Capello, P. Nijkamp, (eds), Handbook of Regional Growth and Development Theories, Edward Elgar, (2009), pp. 182-196

[7] M. Storper: Regional Economies as Relational Assets, Revue d'economie regionale et urbaine (1996)

[8] D. B. Audretsch, T. T Aldrige: Knowledge Spillovers, Entrepreneurship and Regional Development, In: R. Capello, P. Nijkamp, (eds), Handbook of Regional Growth and Development Theories, Edward Elgar, (2009), pp. 201-210

[9] A. J. Scott: Entrepreneurship, Innovation and Industrial Development: Geography and the Creative Field Revisited, 26, 1, (2006), pp. 1-24

[10] C. Antonelli, M. Calderini: The Dynamics of Localized Technological Change, Cambridge University Press (1999)

[11] D. B. Audretsch, M. Fritsch: Growth Regimes over Time and Space, Regional Studies, 36, 2 (2002), pp. 113-124

[12] C. Ruzza: Europe and Civil Society: Movement Coalitions and European Institution, Manchester University Press (2004)

[13] C. Trigilia: Capitale sociale e sviluppo locale, Stato e mercato, n.57, (1999)

[14] Rocha, Sternberg: Entrepreneurship: The Role of Clusters Theoretical Perspectives and Empirical. Evidence from Germany, Small Business Economics 24 (2005), pp. 267-292

[15] G. Becattini: Distretti industriali e made in Italy, Bollati Boringhieri, Torino (1998)

[16] J. S. Coleman: Foundations of Social Theory, Cambridge, Mass., Harvard University Press. (1990)

[17] R. Putnam: Making Democracy Work, Princeton University Press. (1993)

[18] Information on http://ec.europa.eu/research/participants/portal/desktop/en/opportunities/h2020/ topics/2301-isib-03-2015.html 